\title{
Isolation and Characterization of Indigenous Probiotic Bacteria from Silkworm (Bombyx mori L.) Gut
}

\author{
M. Saranya ${ }^{1 *}$, S. V. Krishnamoorthy ${ }^{1}$, D. Balachandar ${ }^{2}$ and M. Tilak ${ }^{3}$ \\ ${ }^{1}$ Department of Sericulture, Forest College and Research Institute, Mettupalayam, India \\ ${ }^{2}$ Department of Agrl. Microbiology, TNAU, Coimbatore, India \\ ${ }^{3}$ Department of Forest products and utilization, Forest College and Research Institute, \\ Mettupalayam, India \\ *Corresponding author
}

\begin{abstract}
A B S T R A C T
Keywords

Silkworm gut samples, culture and biochemical characteristics and lactic acid bacteria

Article Info

Accepted:

24 August 2019

Available Online:

10 September 2019

Lactic acid bacteria are described as heterogeneous group of regular, gram-positive, rod shaped, non-motile, non-spore forming bacteria with absence of catalase enzyme. Laboratory study was undertaken to isolate and characterize the lactic acid bacteria from silkworm gut in phenotype basis. A total of 21 silkworm gut samples were collected from silkworm breeds, Double hybrid \{(CSR 6 X CSR 26) X (CSR 2 X CSR 27) $\}$ obtained from Chawki rearing center (CRC) at Annur, Coimbatore. The bacteria samples were isolated after growth on MRS agar medium and pure culture was obtained by sub-culturing on the same medium. Purity of each culture was confirmed by morphological investigation, Gram's staining and further identification were done by lactic acid bacteria through specific biochemical tests. Finally eight bacterial isolates (SWGL 6, SWGL 7, SWGL 8, SWGL 9, SWGL 10, SWGL 11, SWGL 23 and SWGL 30) were identified as lactic acid bacteria group after morphological, cultural and biochemical characterization.
\end{abstract}

\section{Introduction}

Probiotics are live microbial food supplements used to be beneficial to the host by improving the microbial balance (Fuller, 1991 and Austin et al., 1995). Lactic acid bacteria $(\mathrm{LAB})$ are group of Gram-positive bacteria that are devoid of cytochromes, prefer anaerobic conditions, fastidious, acidtolerant and strictly fermentative. They are usually non-motile and non-sporulating bacteria that produce lactic acid. Several researchers have reported about beneficial role of probiotic in humans (Chan et al., 1985; Douillet and Langton, 1994; Gildberg et al., 1997; Brigidi et al., (2000) and insects (Dillon and Dillon, 2004). Therefore, products containing probiotic bacteria are gaining popularity, increasing their importance. Presence of different types of bacteria in the gut has been already reported in mulberry silkworm (Bombyx mori) (Roy et al., 2000 and Kodama, 2001).

Metchnikoff (1907) first implied that ingested bacteria in the form of fermented foods could 
beneficially affect the normal gut flora. These properties include the beneficial influences that probiotic apparently exert on the microbial ecology of the host (Salminen, 1998). The physicochemical conditions that persuade the composition of the intestinal microbiota include intestinal motility, $\mathrm{pH}$, redox potential, nutrient materials, host secretions (e.g. digestive enzymes, hydrochloric acid, bile and mucus), and the presence of an intact ileocaecal valve (Booijink, 2007). The gastrointestinal (GI) tract harbors many distinct niches, with diverse microbial ecosystem that increases along the GI tract (Gerritsen, 2011). Apart from supporting the digestive functions, indigenous microbes also act as a main actor of the immune system by preventing the colonization by pathogenic microorganisms. Hence, present study was undertaken to isolate and characterize the lactic acid bacteria from silkworm gut samples on the basis of their phenotypic characteristics.

\section{Materials and Methods}

\section{Collection of sample}

Healthy mulberry leaves of variety, V-1 were fed, Double hybrid \{(CSR 6 X CSR 26) X (CSR 2 X CSR 27) \} breed was obtained from Chawki rearing center (CRC) at Annur, Coimbatore. Rearing was done under hygienic conditions with optimum temperature $\left(25-28^{\circ} \mathrm{C}\right)$ and relative humidity (60-70\%). The mulberry leaves were washed thoroughly in running water, shade dried and surface sterilized under UV light before given as feed to silkworms. Leaf feeding was given 3-4 times a day after hatching. Two day old healthy fifth instar larvae were selected and kept under starvation up to 12-16 hours for isolation and enumeration of endogenous gut micro flora. The larvae were anesthetized with 70 per cent chloroform, surface sterilized with 70 per cent alcohol and alimentary canal was dissected out and transferred to water blank. After isolation, the gut was homogenized immediately in $0.1 \mathrm{M}$ potassium phosphate buffer ( $\mathrm{pH} 7.0$ ), washed with glutaraldehyde-free phosphate buffer and preserved at $5^{\circ} \mathrm{C}$ (Breznak, 2000).

\section{Isolation of bacteria}

Isolation was done by using serial dilution method. Serial dilutions of gut samples were prepared and then sample from different dilutions $\left(10^{6}\right.$ to $\left.10^{8}\right)$ were spread over the solidified MRS (de Man, Rogosa, and Sharpe) medium for isolation. Plates were then incubated at $37^{\circ} \mathrm{C}$ for $24-48$ hrs. After incubation isolated colonies were restreaked on MRS agar plate and pure cultures were isolated.

\section{Characterization of isolates}

All the pure cultures samples isolated from silkworm gut were studied for their morphological, cultural and some biochemical characteristics.

\section{Morphological examination}

Morphological examination was carried out by examining colony morphology characteristics of all the isolates.

\section{Culture and biochemical characterization}

Cultural and biochemical characterization of test isolates were done by Gram (1984) staining, motility test, oxidase test, endospore test, catalase and sugar fermentation test. For motility test, sterilized inoculating needles with culture were stab cultured to $2 / 3$ of the way down to the bottom of test tubes containing motility medium. The tubes were incubated at room temperature for $24-48 \mathrm{hrs}$ and observed for the presence or absence of growth along the line of the stab inoculation. 
For endospore test, bacterial smear was aseptically heat fixed on microscopic slide. The slide was placed over steaming water bath and malachite green stain was added for $5 \mathrm{~min}$. The slide was removed and rinsed with tap water. Counter stain safranin was applied for 30 seconds and rinsed with water. Blot dried slides were observed under light microscope for the presence of endospores.

For catalase test, a drop of hydrogen peroxide was taken on a clean glass slide and culture was picked with sterile inoculation loop and slowly immersed into the drop of hydrogen peroxide. Formation of bubbles was observed for positive test. In sugar fermentation test, to $5 \mathrm{ml}$ of nutrient broth (containing $5 \mu \mathrm{l}$ phenol red), $100 \mu \mathrm{l}$ of glucose (1\%) solution was added. The test tubes were inoculated with bacterial culture and incubated at $37^{\circ} \mathrm{C}$ for $24-$ $48 \mathrm{hrs}$. The change in colour of the medium from red to yellow was observed for the positive results of fermentation. In case of homo fermentation production of acid with the change in colour of the medium from red to yellow whereas in hetero fermentation gas production in durham tube are likely.

\section{Results and Discussion}

Twenty one bacteria were isolated from silkworm breeds, Double hybrid \{(CSR 6 X CSR 26) X (CSR 2 X CSR 27) $\}$ from silkworm gut. Test isolates were studied for their morphological characteristics viz., type of colony, colour, surface, margin, elevation, opacity and presence of pigment and the results are presented in Table 1 . Test isolates showed prominent growth on MRS agar after 24-48 $\mathrm{hr}$ of incubation. The colour of colonies ranged from off white, shiny white to creamy white. Margins were entire and undulate in all the isolates. Elevations of the isolated colonies were flat, raised and convex. The opacity of the isolates was translucent and opaque in nature. Further the colour pigments were absent in all pure colonies of isolates and appeared white to creamish in colour. Test cultures of various cultural and biochemical tests studied for identification of lactic acid bacteria viz., motility test, oxidase test, endospore test, catalase and sugar fermentation test are summarized in Table 2. Grams staining of bacterial isolates were done for distinguishing between Gram +ve and Gram -ve bacteria.

The strains exhibited different cell shapes varying from rod to cocci. Out of 21 isolates 8 were Gram +ve rods whereas, 13 isolates were Gram +ve cocci in shape. Motility test showed that the isolates were non-motile, growing in the confined stab line. Endospore test revealed that bacteria were non-endospore forming. Catalase test study showed that in the entire isolates catalase enzyme was absent and they were not able to produce bubbles when mixed with $\mathrm{H}_{2} \mathrm{O}_{2}$. All the isolates were homo fermentative and glucose fermented to acid with change of the colour of medium from red to yellow.

Ten bacterial isolates were identified as Lactic acid bacteria group by morphological, cultural and biochemical characteristic study. The results from the present study were compared with the literature. Ahmed and Kanwal (2004) isolated 11 different strains of lactic acid bacteria from Camel milk and all the strains were non-motile. All the 21 isolates reported in the present study and isolated from different dairy samples were also non-motile. El- Hadi Sulieman et al., (2006) reported that the majority of lactic acid bacteria isolated from Garris (Sudanese traditional fermented camel milk) belongs to the genus Lactobacillus. Forouhanden et al., (2010) isolated 13 lactic acid forming bacteria from different traditional and local cheese and yoghurt. Biochemical characterizations of all the isolates were tested by the utilization of carbon sources. 
Table.1 Morphological characteristics of cultures isolated on MRS agar from silkworm gut

\begin{tabular}{|c|c|c|c|c|c|c|c|c|}
\hline S. No & Isolate name & Shape & Colour & Surface & Margin & Elevation & Pigment & Opacity \\
\hline 1 & SWGL 1 & Circular & Off white & Shiny & Entire & Convex & - & Opaque \\
\hline 2 & SWGL 5 & Circular & Creamy white & Shiny & Entire & Convex & - & Translucent \\
\hline 3 & SWGL 6 & Circular & Creamy white & Smooth & Entire & Raised & - & Translucent \\
\hline 4 & SWGL 7 & Circular & Creamy white & Rough & Entire & Raised & - & Translucent \\
\hline 5 & SWGL 8 & Circular & Off White & Shiny & Undulate & Convex & - & Opaque \\
\hline 6 & SWGL 9 & Circular & Creamy white & Rough & Undulate & Flat & - & Translucent \\
\hline 7 & SWGL 10 & Irregular & Creamy white & Smooth & Undulate & Raised & - & Opaque \\
\hline 8 & SWGL 11 & Circular & Shiny white & Smooth & Entire & Convex & - & Opaque \\
\hline 9 & SWGL 13 & Irregular & Creamy white & Shiny & Undulate & Convex & - & Translucent \\
\hline 10 & SWGL 14 & Circular & Creamy white & Shiny & Entire & Raised & - & Translucent \\
\hline 11 & SWGL 15 & Circular & Creamy white & Smooth & Entire & Convex & - & Opaque \\
\hline 12 & SWGL 16 & Circular & Creamy white & Shiny & Entire & Flat & - & Translucent \\
\hline 13 & SWGL 17 & Irregular & White & Shiny & Undulate & Convex & - & Translucent \\
\hline 14 & SWGL 20 & Circular & Creamy white & Shiny & Entire & Raised & - & Translucent \\
\hline 15 & SWGL 21 & Irregular & Creamy white & Shiny & Undulate & Flat & - & Opaque \\
\hline 16 & SWGL 23 & Circular & Creamy white & Smooth & Entire & Convex & - & Translucent \\
\hline 17 & SWGL 30 & Circular & Creamy white & Shiny & Entire & Convex & - & Translucent \\
\hline 18 & SWGL 32 & Irregular & Creamy white & Shiny & Undulate & Flat & - & Opaque \\
\hline 19 & SWGL 32 & Circular & Creamy white & Smooth & Entire & Convex & - & Opaque \\
\hline 20 & SWGL 34 & Circular & Creamy white & Shiny & Entire & Raised & - & Translucent \\
\hline 21 & SWGL 40 & Irregular & Creamy white & Shiny & Undulate & Raised & - & Opaque \\
\hline
\end{tabular}

Table.2 Culture and biochemical characteristics of pure isolates from silkworm gut samples

\begin{tabular}{|l|l|l|l|l|l|l|l|l|}
\hline $\begin{array}{l}\text { S. } \\
\text { No }\end{array}$ & Isolate name & $\begin{array}{l}\text { Cell } \\
\text { Morphology }\end{array}$ & $\begin{array}{l}\text { Gram } \\
\text { staining }\end{array}$ & $\begin{array}{l}\text { Spore } \\
\text { formation }\end{array}$ & $\begin{array}{l}\text { Catalase } \\
\text { test }\end{array}$ & $\begin{array}{l}\text { Oxidase } \\
\text { test }\end{array}$ & Motility test & $\begin{array}{l}\text { Sugar } \\
\text { fermentation }\end{array}$ \\
\hline $\mathbf{1}$ & SWGL 1 & Rods & + & - & - & - & Non-motile & H \\
\hline $\mathbf{2}$ & SWGL 5 & Cocci & + & - & - & - & Non-motile & H \\
\hline $\mathbf{3}$ & SWGL 6 & Rods & + & - & - & - & Non-motile & H \\
\hline $\mathbf{4}$ & SWGL 7 & Rods & + & - & - & - & Non-motile & H \\
\hline $\mathbf{5}$ & SWGL 8 & Cocci & + & - & - & - & Non-motile & H \\
\hline $\mathbf{6}$ & SWGL 9 & Cocci & + & - & - & - & Non-motile & H \\
\hline $\mathbf{7}$ & SWGL 10 & Rods & + & - & - & - & Non-motile & H \\
\hline $\mathbf{8}$ & SWGL 11 & Cocci & + & - & - & - & Non-motile & H \\
\hline $\mathbf{9}$ & SWGL 13 & Rods & + & - & - & - & Non-motile & H \\
\hline $\mathbf{1 0}$ & SWGL 14 & Cocci & + & - & - & - & Non-motile & H \\
\hline $\mathbf{1 1}$ & SWGL 15 & Cocci & + & - & - & - & Non-motile & H \\
\hline $\mathbf{1 2}$ & SWGL 16 & Rods & + & - & - & - & Non-motile & H \\
\hline $\mathbf{1 3}$ & SWGL 17 & Cocci & + & - & - & - & Non-motile & H \\
\hline $\mathbf{1 4}$ & SWGL 20 & Cocci & + & - & - & - & Non-motile & H \\
\hline $\mathbf{1 5}$ & SWGL 21 & Rods & + & - & - & - & Non-motile & H \\
\hline $\mathbf{1 6}$ & SWGL 23 & Rods & + & - & - & - & Non-motile & H \\
\hline $\mathbf{1 7}$ & SWGL 30 & Rods & + & - & - & - & Non-motile & H \\
\hline $\mathbf{1 8}$ & SWGL 32 & Cocci & + & - & - & - & Non-motile & H \\
\hline $\mathbf{1 9}$ & SWGL 32 & Cocci & + & - & - & - & Non-motile & H \\
\hline $\mathbf{2 0}$ & SWGL 34 & Rods & + & - & - & - & Non-motile & H \\
\hline $\mathbf{2 1}$ & SWGL 40 & Cocci & + & - & - & - & Non-motile & H \\
\hline
\end{tabular}

$+=$ Activity present, $-=$ Negative Test, $\mathrm{H}=$ Homo fermentation 
During fermentation glucose to acid occurred with change in colour from red to yellow. In present study, all isolates showed change in colour of sugar from red to yellow during fermentation of glucose. Goyal et al., (2012) isolated 28 different lactic acid forming bacterial strains from 14 curd samples. All the strains were gram positive, non-spore forming and all of them were catalase negative. Similar observations were reported in the present study.

In the present investigation, 21 bacterial isolates were isolated from silkworm gut. All the isolates were characterized on the basis of colony morphology and biochemical characteristics. Eight bacterial isolates (SWGL 6, SWGL 7, SWGL 8, SWGL 9, SWGL 10, SWGL 11, SWGL 23 and SWGL 30) were identified as lactic acid bacteria by morphological, cultural and biochemical characteristics. Further study of selected lactic acid bacteria isolates by $16 \mathrm{~S}$ rDNA gene sequencing is required for its species identification.

\section{References}

Ahmed T and Kanwal R. 2004. Biochemical characteristics of lactic acid producing bacteria and preparation of camel milk cheese by using starter culture, Pakistan Veterinary Journal, 24.

Austin B. L., F. Stuckney, P. A. W. Robertson, I. Effandi and D.R.W. Griffith. 1995. A probiotic strain of Vibrio alginolyticus effective in reducing diseases caused by Aeromonas salmonicida, Vibrio angullarum and Vibrio ordalli. Journal of Fish Diseases, 18: 93-96.

Booijink CC, El-Aidy S, Rajilic'-Stojanovic M, Heilig HG, Troost FJ, Smidt H. High temporal and inter-individual variation detected in the human ileal microbiota. Environ
Breznek, J. A. 2000. The indigenous gastrointestinal microflora. Trends in Microbiol, 4: 430-433.

Brigidi P., B. Vitali, E. Swennen, L. Altomare, M. Rossi, D.Matteuzzi. 2000. Specific detection of Bifidobacterium strains in a pharmaceutical probiotic product and in human feces by polymerase chain reaction. Applied Microbiology, 23(3): 391-9.

Chan R. C. Y., G. Reid, R. T. Irvin, A. W. Bruce and J. Costerson. 1985. Competitive exclusion of uropathogens from human epithelial cells by Lactobacillus whole cells and cell wall fragments. Infection and Immunity, 47: $84-89$.

Douillet P. and C. J. Langton.1994. Use of a probiotic for the culture of larvae of the pacific oyster (Crassostrea gigas Thunberg). Aquaculture, 119: 25-40

El-Hadi Sulieman AM, Ilayan AA and El Faki AE. 2006. Chemical and microbiological quality of Garris, Sudanese fermented camel's milk product. International Journal of Food Science and Technology, 41:321-328.

Forouhandeh H, Vahed ZS, Hejazi MS, Nahaei MR and Dibavar MK. 2010. Isolation and Phenotypic Characterization of Lactobacillus species from various dairy products, Current Research in Bacteriology, 3:8488.

Fuller R. 1991. Probiotics in human medicine. Gut; 32(4): 439- 42.

Gerritsen J, Smidt H, Vos WM and Rijkers GT. 2011. Intestinal microbiota in human health and disease: the impact of probiotics. Genes Nutr, 6:209-40.

Gildberg A., H. Mikkelsen, E. Sandker and E. Ringo. 1997. Probiotic effect of lactic acid bacteria in the feed on the growth and survival of fry of Atlantic cod (Gadus morthua). Hydrobiologia, 352: 279- 285 
Goyal R, Dhingra H, Bajpai P and Joshi N. 2012. Characterization of the Lactobacillus isolated from different curd samples. African Journal of Biotechnology, 11: 14448-14452.

Kodama R. 2001. Bacterial diseases and counter measures chapter IV Silkworm rearing and artificial diet Editor Hamamura $Y$ Oxford and IBH publishing Co. Pvt. Ltd. New Delhi Calcutta.

Metchnikoff E. 2010. The prolongation of life. Optimistic studies 2nd ed. London. Microbiol, 12(12):3213-27.
Roy D. K., D. N. Sahay, S. Rai, B.R.R.Pd. Sinha and K. Thangavelu. 2000. National conference on strategies for sericulture research and development at Central sericultural research and training institute central silk board (Ministry of textiles) Govt. of India Srirampura, Mysore.16-18 November Abstract No.Mmspp/0-7, Pp87.

Salminen S, Deighton MA, Benno $\mathrm{Y}$ and Gorbach SL. 1998. Lactic acid bacteria in health and disease: microbiology and functional aspects. 2nd ed. NewYork: Marcel Dekker Inc, Pp. 211- 54.

\section{How to cite this article:}

Saranya M., S. V. Krishnamoorthy, D. Balachandar and Tilak M. 2019. Isolation and Characterization of Indigenous Probiotic Bacteria from Silkworm (Bombyx mori L.) Gut. Int.J.Curr.Microbiol.App.Sci. 8(09): 2869-2874. doi: https://doi.org/10.20546/ijcmas.2019.809.329 